\title{
Study on strata behavior law of deep inclined coal seam
}

\author{
Chen Zhengwen ${ }^{1,2}$ \\ ${ }^{1}$ Shandong University of Science and Technology National Key Laboratory Cultivation Base for Mine Disaster Prevention and Control, \\ Shandong Province, Qingdao 266590 \\ ${ }^{2}$ Shandong University of Science and Technology School of Energy and Mining Engineering, Qingdao, Shandong 266590
}

\begin{abstract}
In order to understand and grasp the law of roof pressure on the working face of deep inclined coal seams, the law of support resistance distribution, the law of leading support stress distribution and the law of surrounding rock deformation of the two roadways, the 94101 working face of Zhangshuanglou Coal Mine was taken as the engineering background.Through a combination of field measurement, numerical simulation, theoretical analysis, etc, this paper analyzes the laws of roof migration and rock pressure manifestation in deep inclined coal seams.
\end{abstract}

\section{Introduction}

In the era of rapid economic growth, the status of energy has become more important. Coal resources play an important role in the development of our country. However, continuous integration and development are also needed to ensure the stable development of our society ${ }^{[1]}$. The law of the appearance of pressure in deep inclined coal seams is different from that of conventional working faces, and the frequent occurrence of accidents of the appearance of pressure in the mine brings serious harm to the sustainable production of the mine and worker safety ${ }^{[2,3]}$.Therefore, it is necessary to conduct in-depth research on the breaking law of the overlying rock mass and the behavior of rock pressure in the deep inclined coal seam. It is possible to monitor and analyze the working resistance of the hydraulic support on the working face, and monitor the advance supporting stress and the deformation of the surrounding rock of the Liuzi road and the material road, so as to find the asymmetry and the imbalance of the rock pressure in the inclined direction and the strike direction of the working face. Support work resistance monitoring can infer the movement state of the roof covering on the working surface. By screening the end-of-cycle resistance of each coal cutting cycle, the law of the end-of-cycle resistance can be analyzed to determine the law of movement of the roof ${ }^{[4]}$. The borehole stress can monitor and analyze the change law of the stress field in front of the coal wall of the working face, obtain the high stress area and its corresponding change characteristics, and realize the real-time monitoring of the rock pressure ${ }^{[5-9]}$.

\section{Engineering background}

The buried depth of 94101 working face is about $1000 \mathrm{~m}$, the average thickness of coal seam is $3.1 \mathrm{~m}$, the development of coal seam is stable, the hardness of coal quality is $2 \sim 3$, and the coal seam and roof and floor have impact tendency; The working face has a strike length of $1,120 \mathrm{~m}$, a tendency average length of $188.3 \mathrm{~m}$, and a coal seam dip angle of 28 on average. The longwall retreating mining technology is adopted, and the double roadway layout is adopted, which is adjacent to the goaf of 9121 working face in the south. The model of shearer in 94101 working face is MG450/1020-WD, the model of hydraulic support is ZY6800-20/42, the rated working resistance of support is $6800 \mathrm{kN}$, and the model of scraper is SGZ1000/1050. See table 1 and table 2 for index value of strong impact tendency of No. 9 coal.

Table 1. Physical properties of coal seam.

\begin{tabular}{|c|c|}
\hline Seam number & 9\# coal seam \\
\hline Serial number & Average value \\
\hline Apparent density/ $\mathbf{k g} \cdot \mathbf{m}^{-3}$ & 1326 \\
\hline True density/kg $\cdot \mathbf{m}^{-3}$ & 1426 \\
\hline Moisture content $/ \%$ & 2.84 \\
\hline Natural water absorption/\% & 7.20 \\
\hline
\end{tabular}

Table 2. Physical properties of surrounding rock

\begin{tabular}{|c|c|c|}
\hline Seam number & 9\# coal seam & 9\# coal seam \\
\hline Serial number & $\begin{array}{c}\text { Average } \\
\text { value }\end{array}$ & $\begin{array}{c}\text { Average } \\
\text { value }\end{array}$ \\
\hline $\begin{array}{c}\text { Apparent density/kg } \cdot \mathbf{m}^{-} \\
\mathbf{3}\end{array}$ & 2685 & 2567 \\
\hline True density/kg $\cdot \mathbf{m}^{-3}$ & 2775 & 2651 \\
\hline
\end{tabular}

\footnotetext{
" Chen Zhengwen:569069738@qq.com
} 


\begin{tabular}{|c|c|c|}
\hline Moisture content/\% & 0.56 & 1.23 \\
\hline $\begin{array}{c}\text { Natural water } \\
\text { absorption/\% }\end{array}$ & 0.90 & 2.70 \\
\hline
\end{tabular}

\section{Field measurement research}

Through monitoring and analyzing the characteristics of rock pressure in 94101 working face, it is found that the rock pressure behavior in 94101 working face is asymmetric and unbalanced, and the rock pressure behavior in the upper part of the working face and the material channel is stronger than that in the middle and lower part and the chute, which increases the possibility of impact behavior in the upper part of the working face and the material channel.

\subsection{Monitoring purpose}

In order to fully understand and master the roof weighting law, support resistance distribution law, advance support stress distribution law and surrounding rock deformation law of two roadways in fully mechanized coal mining face in deep inclined seam, the similarities and differences of mine pressure behavior in different areas of the working face inclination direction were found, and the intensity of mine pressure behavior in material roadway and valve roadway was found, which further provided basis for surrounding rock control.

\subsection{Monitoring contents}

1) Continuous monitoring of support resistance of hydraulic support in working face. Its characteristic data mainly include initial supporting force and cyclic working resistance.

2) Statistical observation of working face. It mainly includes the initial weighting step and the periodic weighting step of the basic roof in different areas of the inclined direction of the working face.

3) Advance mine pressure observation of roadway, mainly including advance bearing stress of material tunnel and valve tunnel and deformation of surrounding rock of roadway.

\subsection{Monitoring methods}

1) Monitoring of working resistance of hydraulic support in working face

A total of 24 roof pressure monitoring substations are arranged in the working face, and each monitoring substation is provided with two monitoring channels, which are respectively connected with the two columns of the support. According to the actual situation, the working face is divided into three measuring areas, which are the lower measuring area, the middle measuring area and the upper measuring area. The lower survey area contains 8 monitoring substations, which are installed on supports $10 \#, 11 \#, 12 \#, 13 \#, 14 \#, 15 \#, 16 \#$ and $17 \#$ respectively. There are 8 monitoring substations in the central survey area, which are installed on brackets $60 \#, 61 \#, 62 \#, 63 \#$, $64 \#, 65 \#, 66 \#$ and $67 \#$ respectively. There are 8 monitoring substations in the upper measuring area, which are respectively installed on supports $100 \#, 101 \#, 102 \#$, 103\#, 104\#, 105\#, 106\# and 107\#, and the working resistance of 24 supports is monitored and recorded in real time and transmitted.

2) Monitoring of advanced bearing stress

The monitoring of advanced bearing stress is carried out by coal stress meter, which is connected with monitoring substation. There are 16 groups of measuring stations, with material channel numbers 3001 \# 3008 \# and valve channel numbers 3009 \# 3016 \#, with a spacing of $25 \mathrm{~m}$. The first group of measuring points is $25 \mathrm{~m}$ away from the cut, and each group of measuring stations contains two drilling holes with a depth of $8 \mathrm{~m}$ and $14 \mathrm{~m}$, with a hole spacing of $1.5 \mathrm{~m}$ The stress meter needs to be laid in advance in the advanced coal seam. The monitoring substation moves forward with the mining of the working face, and the data of the stress meter can be monitored in real time by the upper computer.

The stress gauge sensor is mainly composed of drilling stress pillow and inclusion, with the maximum thickness of $38 \mathrm{~mm}$. By filling oil into the hydraulic oil pillow and increasing pressure, the inclusion expands, and the stress gauge can fully contact with the surrounding coal wall. The length of the pressure guiding oil pipe connected with the two drilling sensors of $8 \mathrm{~m}$ and $14 \mathrm{~m}$ is $9 \mathrm{~m}$ and $15 \mathrm{~m}$ respectively, the stress measurement range is $0 \sim 60 \mathrm{MPa}$, and the initial stress value is set at 3.0MPa.

3) Monitoring of surrounding rock deformation

The deformation of surrounding rock is measured by cross observation method, and a set of measuring points are respectively arranged at $150 \mathrm{~m}$ of the advanced working face of the material road and the valve road, which are observed three times a week in the early stage and monitored once a day in the later stage. The observation frequency is determined according to whether it is affected by mining. Generally, it is within $50 \mathrm{~m}$ from the working face and observed once a day, especially when it is within $10 \mathrm{~m}$ from the working face, it should be observed many times a day. At other times, it can be observed $2 \sim 3$ times a week according to the site conditions.

\subsection{Result analysis}

By analyzing and sorting out a number of data in three different areas of inclined working face, the following conclusions can be drawn:

1) Initial supporting force of hydraulic support

Statistics show that the initial supporting force of 24 supports monitored in three areas of the working face ranges from $1563 \sim 3957 \mathrm{kN}$ to $3957 \mathrm{kN}$, with an average value of $3300 \mathrm{kN}$ in the whole area, $3353 \mathrm{kN}$ in the upper area, $3222 \mathrm{kN}$ in the middle area and $3324 \mathrm{kN}$ in the lower area, accounting for $65.1 \%, 66.2 \%, 63.6 \%$ and $65.6 \%$ of the rated initial supporting force respectively.

The mean value of mean square deviation of initial bracing force is 360 in the whole region, 355 in the upper region, 377 in the middle region and 347 in the lower 
region, which account for $10.9 \%, 10.5 \%, 11.7 \%$ and $10.4 \%$ of the mean value of initial bracing force in each region, respectively.

According to the actual target requirement that the initial supporting force of the support working face needs to reach $80 \%(4051 \mathrm{kN})$ of the rated initial supporting force, the utilization rate of the initial supporting force of the support working face is low, so it is necessary to give greater initial supporting force at the time of initial supporting.

2) End-of-cycle resistance of hydraulic support

The statistical end-of-cycle resistance of 24 supports monitored in three areas of the working face ranges from $3,357 \mathrm{kN}$ to $6,970 \mathrm{kN}$, with an average value of $4886 \mathrm{kN}$ in the whole area, $5009 \mathrm{kN}$ in the upper area, $4832 \mathrm{kN}$ in the middle area and $4816 \mathrm{kN}$ in the lower area. The pressure value in the upper area is the largest, and the average value of end-of-cycle resistance of supports in the three areas does not exceed the rated working resistance, accounting for $71.8 \%$ of the rated working resistance respectively.

The mean value of mean square deviation of end-ofcycle resistance is 539.17 in the whole region, 598.46 in the upper region, 507.34 in the middle region, and 511.70 in the lower region, among which the mean square deviation of end-of-cycle resistance in the upper region is the largest and the mean square deviation of end-of-cycle resistance in the middle region is the smallest, accounting for $11.9 \%$ and $11.9 \%$ of the end-of-cycle resistance in each region respectively.

3) Pressure value of roof weighting process

The pressure value of roof weighting process of 24 supports monitored in three areas of the working face ranges from $4900 \sim 6970 \mathrm{kN}$ to $6970 \mathrm{kN}$, and the average value of the whole area is $5782 \mathrm{kN}$, the average value of the upper area is $5994 \mathrm{kN}$, the average value of the middle area is $5624 \mathrm{kN}$, and the average value of the lower area is $5727 \mathrm{kN}$, accounting for $85.0 \%, 88.1 \%, 82.7 \%$ and 84 of the rated working resistance respectively.

The mean square deviation of support working resistance in the whole region is $311.17,335.45$ in the upper region, 309.18 in the middle region and 288.90 in the lower region.

4) Pressure value of roof in relatively stable stage

The pressure values of the roof of 24 supports monitored in three areas of the working face during the relatively stable stage range from $3,357 \mathrm{kN}$ to $6,274 \mathrm{kN}$, with an average value of $4662 \mathrm{kN}$ in the whole area, $4743 \mathrm{kN}$ in the upper area, $4623 \mathrm{kN}$ in the middle area and $4620 \mathrm{kN}$ in the lower area, accounting for $68.5 \%, 69.7 \%$, $67.9 \%$ and $660 \mathrm{kN}$ of the rated working resistance respectively Among them, the pressure value of the roof in the upper region is the largest during the relatively stable period, which is about $100 \mathrm{kN}$ higher than that in the middle and lower regions, and the utilization rate of supporting resistance is relatively low at this stage.

The mean square deviation of support working resistance in the whole region is 295.63, that in the upper region is 295.03, that in the middle region is 292.70 and that in the lower region is 299.16.

5) Basic roof initial pressure interval
According to statistics, the basic top initial weighting steps of 24 supports monitored in three areas of the working face range from $33.6 \mathrm{~m}$ to $46.4 \mathrm{~m}$, with an average of $39.03 \mathrm{~m}$ in the whole area, $36.8 \mathrm{~m}$ in the upper area, $38.1 \mathrm{~m}$ in the middle area and $42.1 \mathrm{~m}$ in the lower area, among which the first weighting step in the lower area is the largest.

The basic roof initial weighting duration ranges from 1.7 to $4.8 \mathrm{~m}$, with an average of $3.14 \mathrm{~m}$ in the whole region, $2.82 \mathrm{~m}$ in the upper region, $3.27 \mathrm{~m}$ in the middle region and $3.32 \mathrm{~m}$ in the lower region, among which the first weighting duration in the lower region is the largest, followed by the middle region and the smallest in the upper region.

6) Basic top cycle weighting step

The statistical range of the basic top periodic weighting steps of 24 supports monitored in three areas of the working face is $11.2 \sim 21.6 \mathrm{~m}$, which is equivalent to $14 \sim 27$ coal cutting knives. The average value of the periodic weighting steps in the whole area is $15.7 \mathrm{~m}$, equivalent to 20 coal cutting knives, the average value of the periodic weighting steps in the upper area is $14.5 \mathrm{~m}$, equivalent to 19 coal cutting knives, and the average value of the periodic weighting steps in the middle area is 15.5. The average periodic weighting interval in the lower area is $17.6 \mathrm{~m}$, which is equivalent to 22 coal cutters, among which, the periodic weighting interval in the lower area is the largest, with an average of $2 \mathrm{~m}$ larger than that in the middle area and $3.1 \mathrm{~m}$ larger than that in the upper area.

The mean square deviation of the basic top cycle weighting step ranges from 0.4 to 3.6 , with the mean square deviation of 1.9 in the whole region, $2.0 \mathrm{~m}$ in the upper region, 1.5 in the middle region and 2.3 in the lower region, among which the mean square deviation of the lower region is the largest, and the discrete type is relatively large, followed by the upper region and the middle region is the smallest.

7) Significant movement step of basic roof

The range of significant movement steps of 24 supports monitored in three areas is $1.6 \sim 5.6 \mathrm{~m}$, which is equivalent to $2 \sim 7$ coal cutting knives. The average of significant movement steps in the whole area is $3.8 \mathrm{~m}$, equivalent to 5 coal cutting knives, the average of significant movement steps in the upper area is $4.0 \mathrm{~m}$, equivalent to 5 coal cutting knives, and the average of significant movement steps in the middle area is $3.8 \mathrm{~m}$, equivalent to 5 coal cutting knives.

Among them, the significant movement step of the basic top of the $13 \#$ support has the largest change, which is $2.4 \sim 5.6 \mathrm{~m}$, the difference between the maximum and the minimum is $3.2 \mathrm{~m}$, the mean square error is $2.0 \mathrm{~m}$, and the dispersion is the largest.

8) Monitoring and analysis of material channel and valve channel

Through the monitoring and analysis of the leading bearing stress of the material tunnel and the valve tunnel, it can be seen that the leading bearing stress of the material tunnel has an influence range of $120 \sim 150 \mathrm{~m}$, and the maximum stress peak value is $32.7 \mathrm{MPa}$. At a distance of $14 \mathrm{~m}$ from the coal wall, the degree of change is relatively large within $30 \mathrm{~m}$, and within $30 \sim 70 \mathrm{~m}$; The influence range of the leading bearing stress of the valve track is 130 
$\sim 160 \mathrm{~m}$, with the maximum stress peak value of $29.6 \mathrm{MPa}$. It changes greatly within $35 \mathrm{~m}$ from the coal wall, and it changes stably within $35 \sim 80 \mathrm{~m}$, and the stress peak value of the material track is larger, so stress monitoring and support of the material track should be strengthened.

After monitoring and analyzing the deformation of surrounding rock of material roadway and valve roadway, it can be seen that the deformation of surrounding rock is faster when it is $50 \mathrm{~m}$ away from the working face, and the support and monitoring should be strengthened at this time, and the deformation of surrounding rock will basically remain stable after mining to $150 \mathrm{~m}$; The deformation amount and deformation rate of surrounding rock of material tunnel are larger than that of the chute. The maximum displacement of roof and floor and two sides of the chute are $1508 \mathrm{~mm}$ and $1206 \mathrm{~mm}$ respectively, and the maximum displacement of roof and floor and two sides of the chute are $1093 \mathrm{~mm}$ and $897 \mathrm{~mm}$ respectively.

\section{Theoretical analysis and research}

In 94101 working face of Zhangshuanglou Coal Mine, the upper section of the working face is the goaf of 9121 working face, with solid coal on the road side, small coal pillar to protect the roadway on the material roadway side, and the width of coal pillar is $5 \mathrm{~m}$. Because of the special conditions of deep inclined small coal pillar to protect the roadway, the overlying rock mass is in a different motion state from the ordinary stope. On the material roadway side, after the upper section coal seam was mined, all the direct roofs above the roadway did not directly collapse into the upper section goaf. Instead, a special filling structure is formed, and the overlying strata break and collapse. The goaf state formed by the upper section working face will affect the mining characteristics of this section. The fracture structure of the overlying rock mass during the mining of 94101 working face is shown in Figure 1.

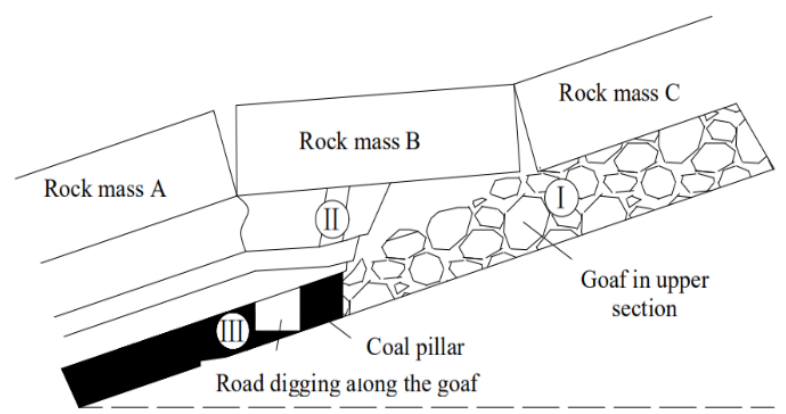

Fig. 1. Fracture structure of overlying rock mass during mining in 94101 working face.

When mining 94101 working face, because the support keeps moving forward with the coal mining, the top of the support will collapse after moving, but because 94101 working face is an inclined coal seam with small coal pillars to protect the roadway, the direct roof will collapse irregularly below the rock block B and above the rock block A. After that, the fracture of the basic roof will be affected to a certain extent, and the movement of the overlying strata will be different from that of the horizontal coal seam. However, rock block ABC will form an articulated structure, and the key block of this structure is rock block $\mathrm{B}$, which plays a very important role in the stability of the whole structure, so it is necessary to discuss rock block B in detail.

\subsection{Mechanical model of key block structure of surrounding rock}

The 94101 working face is adjacent to the goaf of the 9121 working face in the south and the solid coal side in the north. In the process of back mining, the upper section will form a rock block hinged structure as shown in Figure 1, forming an arc triangle block B.

1) research on b parameters of arc triangle block

The special structure formed by the working face of deep inclined coal seam is closely related to the physical and mechanical properties of overlying strata. Further, the physical and mechanical properties of direct roof, basic roof and coal seam determine the parameters of this structure. This paper mainly considers the influence of the length L1 of rock block B in strike direction and the length $L_{2}$ in dip direction on mining in this section. The top view of arc triangle block B in this section is shown in Figure.

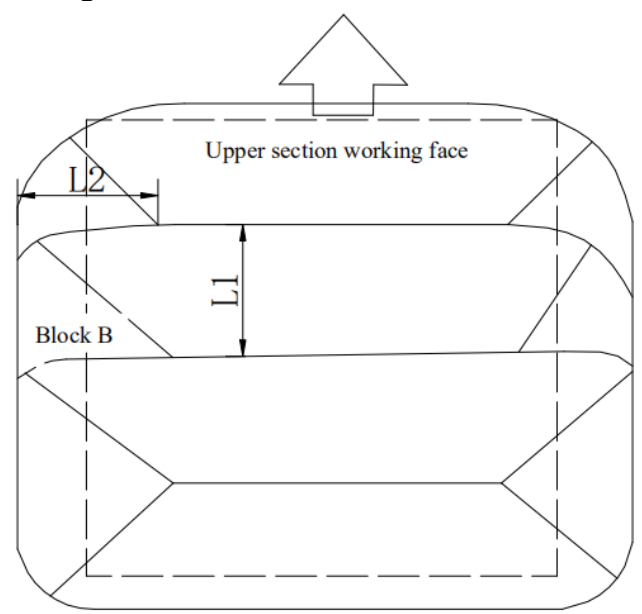

Fig. 2. Top view of arc triangle block B

It can be analyzed from fig. 2 that the length $L_{1}$ of the arc triangle block $b$ in the strike direction is consistent with the pressing step distance of the basic top period, and the results of field observation and theoretical calculation can be referred. $L_{l}$ can be calculated by Formula 1:

$$
L_{1}=h \sqrt{\frac{R_{t}}{3 q}}
$$

In which: $h$ - the basic roof thickness, $\mathrm{m} ; R_{t}$ - the tensile strength of basic roof, $\mathrm{MPa} ; q$-the load per unit area of the basic roof, MPa.

$L_{2}$ represents the parallel component along the inclined coal seam working face. According to the plate yield line analysis method, it can be determined that $L_{2}$ is closely related to the length $\mathrm{s}$ of the inclined coal seam working face and the basic roof periodic weighting step $L_{2}$. Therefore, the length of $L_{2}$ can be calculated by Formula 2:

$$
L_{2}=\frac{2 L_{1}}{17}\left[\sqrt{\left(10 \frac{L_{1}}{S}\right)+102}-\frac{L_{1}}{S}\right]
$$


The lateral fracture span of the basic roof in longwall retreating mining face is approximately equal to the periodic weighting step of the basic roof, and the suspension span $L_{2}$ of the 94101 arc triangle block B is 12 $\sim 19 \mathrm{~m}$.

Roadway driving along goaf in deep inclined coal seam, the rock above the roadway is constantly changing with the mining of working face, and its arc triangle block B is located above the material tunnel of 94101 working face, which can be approximately considered as the function of a bridge. In different mining stages, it is particularly important to the mining of this section, and its stress range is relatively large, which further affects the motion state of other rock masses and forms a dynamic change process.

\section{Numerical simulation research}

In the process of mining in the working face, the original rock stress of the stope changes due to the influence of mining. With the continuous advancement of the working face, the surrounding rock stress is constantly in the process of alternating balance and failure, and the surrounding rock in front of and above the working face is constantly damaged by tension and compression, and the range is continuously increased until the stress release occurs. For the mining of deep inclined coal seam, the phenomenon of stress release also exists, which is different from that of horizontal coal seam and easy to cause dynamic disaster. Therefore, this section takes the 94101 working face in Zhangshuanglou Coal Mine as the research background, and carries out numerical simulation research and analysis on the stope in the process of pushing mining.

According to the existing mechanical characteristics of rock mass, in the mining process of deep inclined coal seam working face, rock mass and coal seam will be damaged and destroyed to some extent, and then elasticplastic deformation will occur. Rock mass and coal seam have certain physical properties and can still bear a certain range of forces after receiving damage and destruction. Based on this, the elastic-plastic constitutive model is the first choice model for this numerical simulation, i.e. MohrCoulomb yield criterion, as shown in Formula 3.

$$
f_{s}=\sigma_{1}-\sigma_{3} \frac{1+\sin \varphi}{1-\sin \varphi}-2 C \sqrt{\frac{1+\sin \varphi}{1-\sin \varphi}}
$$

Where: $\sigma_{l}-$ maximum principal stress, $\mathrm{MPa} ; \sigma_{2}-$ minimum principal stress, $\mathrm{MPa} ; C$-cohesion, $\mathrm{MPa} ; \varphi$ internal friction angle, ${ }^{\circ}$.

According to the geological conditions of 94101 working face in Zhangshuanglou Coal Mine, the original rock stress is unbalanced and redistributed after mining by using numerical simulation software, which leads to the change of mechanical parameters of surrounding rock, forming plastic zone and even instability. According to the comprehensive histogram and geological data of coal seam in 94101 working face, the length of working face is simplified to $180 \mathrm{~m}$ and the thickness of coal seam is simplified to $3.0 \mathrm{~m}$. Establish a model with a dip angle of 30 , and the mining height is $3.0 \mathrm{~m}$. According to the real geological data and practical experience, the model is established, and the length $\times$ width $\times$ height of the model is $330 \mathrm{~m} \times 200 \mathrm{~m} \times 280 \mathrm{~m}$. The simulation is divided into two mining steps, the first mining is the mining in the upper section, which is $80 \mathrm{~m}$ along the dip direction, and the second mining is the mining in this section, with a mining step of $15 \mathrm{~m}$ each time. The roof displacement, vertical stress and other parameters of the 94101 working face are recorded. The stress boundary conditions of the model are as follows: the average buried depth of the upper boundary of the model is $1000 \mathrm{~m}$, the displacement of the bottom surface and its surroundings is fixed, the uniformly distributed compressive stress of $25 \mathrm{MPa}$ is applied to the upper boundary of the model, and the lateral compressive coefficient is 0.30 .

By studying the roof stress and displacement in the inclined direction of coal seam, we can see the distribution of stress and displacement in the inclined direction more intuitively, and mainly study the distribution of stress and displacement in the inclined direction of coal seam when the advancing distance is $15 \mathrm{~m}, 30 \mathrm{~m}, 45 \mathrm{~m}, 60 \mathrm{~m}, 75 \mathrm{~m}, 90 \mathrm{~m}$, 105 and $120 \mathrm{~m}$. Through the numerical simulation of displacement in the inclined direction, the stress distribution nephogram in the inclined direction is shown in Figure 3, and the displacement distribution nephogram in the inclined direction is shown in Figure 4.

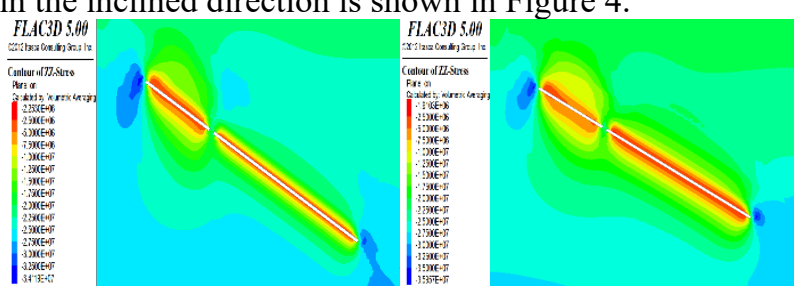

(a) Stoping $15 \mathrm{~m}$

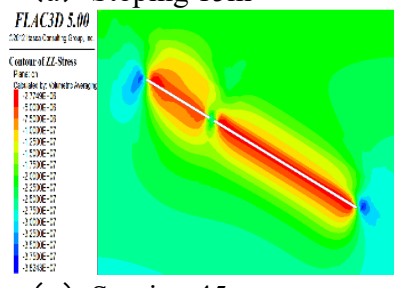

(c) Stoping $45 \mathrm{~m}$

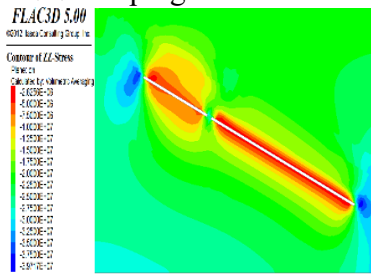

(e) Stoping $75 \mathrm{~m}$

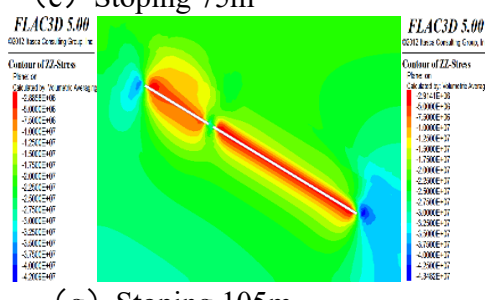

(g) Stoping $105 \mathrm{~m}$ (b) Stoping $30 \mathrm{~m}$

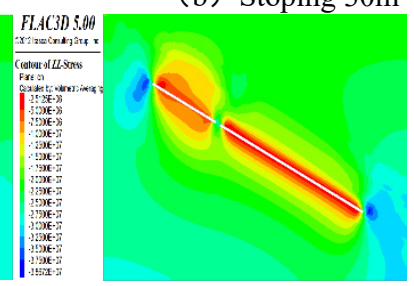

(d) Stoping $60 \mathrm{~m}$
$120 \mathrm{~m}$

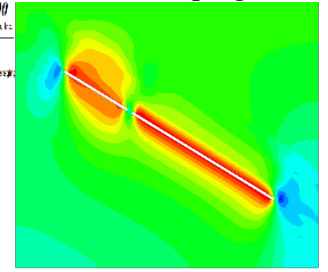

(f) Stoping $90 \mathrm{~m}$

Fig. 3. Distribution of stress nephogram at different advancing distances in inclined direction

1) Roof stress analysis

Through the concrete analysis of the vertical stress distribution of roof at $15 \mathrm{~m}, 30 \mathrm{~m}, 45 \mathrm{~m}, 60 \mathrm{~m}, 75 \mathrm{~m}, 90 \mathrm{~m}$, 
105 and $120 \mathrm{~m}$, it can be seen that the stress release range of overlying strata in goaf and the pressure relief range of floor in lower area also increase with the advancing distance, but the pressure relief area in lower area is smaller than that in upper area. When the working face is mined to $15 \mathrm{~m}, 30 \mathrm{~m}, 45 \mathrm{~m}, 60 \mathrm{~m}, 75 \mathrm{~m}, 90 \mathrm{~m}, 105$ and $120 \mathrm{~m}$, the stress value and stress concentration coefficient in the upper, middle and lower areas of the working face are all increasing. When the working face is mined to $15 \mathrm{~m}$, the maximum vertical stress of the roof of the inclined coal seam working face reaches $34.11 \mathrm{MPa}$, and the stress concentration coefficient is 1.36 . When the working face is mined to $30 \mathrm{~m}$, the maximum vertical stress of roof in inclined coal seam working face reaches $35.96 \mathrm{MPa}$, and the stress concentration coefficient is 1.43; when the working face is mined to $45 \mathrm{~m}$, the maximum vertical stress of roof in inclined coal seam working face reaches $38.24 \mathrm{MPa}$, and the stress concentration coefficient is 1.52 ; when the working face is mined to $60 \mathrm{~m}$, the maximum vertical stress of roof in inclined coal seam working face reaches $38.67 \mathrm{MPa}$, and the stress concentration coefficient is 1.54 ; when the working face is mined to $75 \mathrm{~m}$, the maximum vertical stress of roof in inclined coal seam working face reaches $39.71 \mathrm{MPa}$, and the stress concentration coefficient is 1.58; when the mining face reaches $90 \mathrm{~m}$, the maximum vertical stress of roof in inclined coal seam face reaches $40.81 \mathrm{MPa}$, and the stress concentration coefficient is 1.63; when the mining face reaches $105 \mathrm{~m}$, the maximum vertical stress of roof in inclined coal seam face reaches $42.00 \mathrm{MPa}$, and the stress concentration coefficient is 1.68; when the mining face reaches $120 \mathrm{~m}$, the maximum vertical stress of roof in inclined coal seam face reaches $43.48 \mathrm{MPa}$, and the stress concentration coefficient is 1.73 .

The vertical stress nephogram of roof in inclined coal seam working face is asymmetrically distributed. along the inclined direction of working face, the vertical stress in the lower area of working face is smaller than that in the upper area of working face. the maximum value of stress concentration area is located at the junction of middle area and upper area. the maximum value of vertical stress in the upper area reaches $49.26 \mathrm{MPa}$, and the minimum vertical stress is $35.15 \mathrm{MPa}$, with a difference of $14.11 \mathrm{MPa}$. The maximum vertical stress in the middle region reaches $46.52 \mathrm{MPa}$ and the minimum vertical stress is $33.28 \mathrm{MPa}$, with a difference of $13.24 \mathrm{MPa}$. The maximum vertical stress in the lower region reaches $45.63 \mathrm{MPa}$ and the minimum vertical stress is $32.65 \mathrm{MPa}$, with a difference of 12.98MPa.

2) Roof displacement analysis

Through the numerical simulation of roof displacement at different distances in the inclined direction of the working face, it can be seen more intuitively that the upper section of the working face has certain influence on the lower section of the working face during the mining process of the deep inclined coal seam with small coal pillars, which changes the displacement and influence range of the overlying roof surrounding rock in the mining of the lower section of the working face to a certain extent. By comparing and analyzing the analysis of roof displacement at different advancing distances, the following conclusions can be drawn.

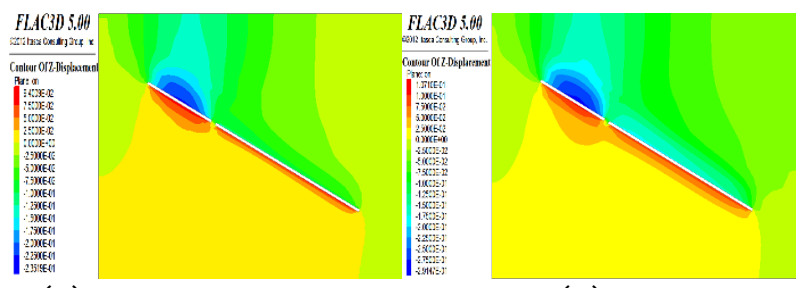

(a) Stoping $15 \mathrm{~m}$
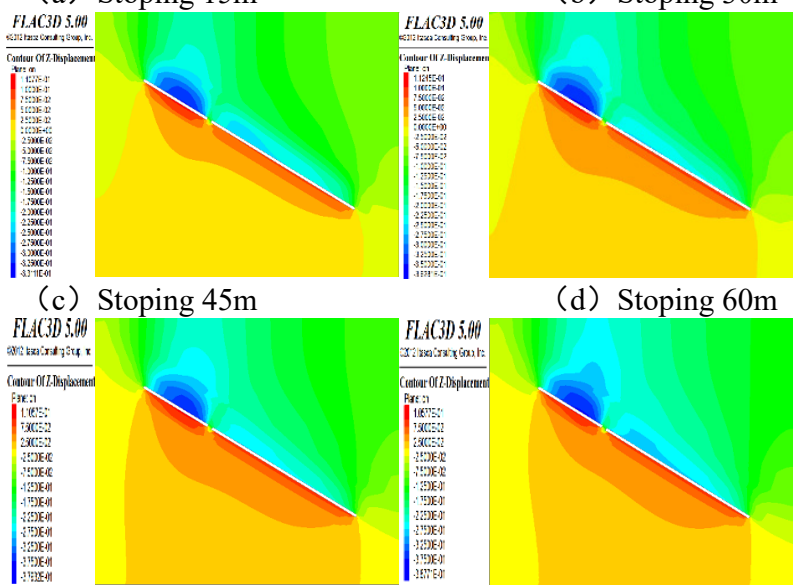

(e) Stoping $75 \mathrm{~m}$

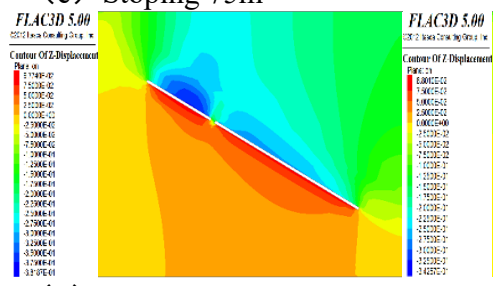

(g) Stoping $105 \mathrm{~m}$

(f) Stoping $90 \mathrm{~m}$

Fig. 4. Distribution of displacement nephogram with different advancing distance in inclined direction

Through the concrete analysis of displacement distribution figure 4 at $15 \mathrm{~m}, 30 \mathrm{~m}, 45 \mathrm{~m}, 60 \mathrm{~m}, 75 \mathrm{~m}, 90 \mathrm{~m}$, 105 and $120 \mathrm{~m}$, it can be known that the vertical displacement of overlying strata in goaf also increases with the advancing distance in the continuous mining process of the working face. When the working face is mined to $15 \mathrm{~m}$, the maximum vertical displacement of the roof reaches $235.1 \mathrm{~mm}$; when the mining face reaches $30 \mathrm{~m}$, the maximum vertical displacement of the roof reaches $291.4 \mathrm{~mm}$; when the mining face reaches $45 \mathrm{~m}$, the maximum vertical displacement of the roof reaches $331.1 \mathrm{~mm}$; when the working face is mined to $60 \mathrm{~m}$, the maximum vertical displacement of the roof reaches $362.8 \mathrm{~mm}$; when the working face is mined to $75 \mathrm{~m}$, the maximum vertical displacement of roof reaches $379.3 \mathrm{~mm}$; when the mining face reaches $90 \mathrm{~m}$, the maximum vertical displacement of the roof reaches $387.7 \mathrm{~mm}$; when the mining face reaches $105 \mathrm{~m}$, the maximum vertical displacement of the roof reaches $381.8 \mathrm{~mm}$; when the mining face reaches $120 \mathrm{~m}$, the maximum vertical displacement of the roof reaches $342.5 \mathrm{~mm}$; through the analysis, it can be seen that the displacement and subsidence of roof in the vertical direction change greatly before the mining face reaches $75 \mathrm{~m}$. When the working face is mined to $30 \mathrm{~m}$, the maximum displacement of the roof is $56.3 \mathrm{~mm}$ larger than that when it is mined to $15 \mathrm{~m}$, and the maximum displacement increases by about 0.23 times; when the mining face reaches $60 \mathrm{~m}$, the maximum 
displacement of roof is $71.4 \mathrm{~mm}$ larger than that when the mining face reaches $30 \mathrm{~m}$, and the maximum displacement increases by about 0.24 times. When the working face is mined to $90 \mathrm{~m}$, the maximum displacement of the roof is $24.9 \mathrm{~mm}$ larger than that when it is mined to $60 \mathrm{~m}$, and the maximum displacement increases by about 0.06 times; when the mining face reaches $120 \mathrm{~m}$, the maximum displacement of the roof is $42.5 \mathrm{~mm}$ smaller than that when the mining face reaches $90 \mathrm{~m}$, and the maximum displacement decreases by about 0.11 times.

Roof displacement nephogram of inclined coal seam working face is asymmetrically distributed, and the displacement in the lower part of working face is smaller than that in the upper part of working face. The maximum vertical displacement in the upper part reaches $503.2 \mathrm{~mm}$, the minimum displacement is $125.8 \mathrm{~mm}$, the difference is $377.4 \mathrm{~mm}$, and the maximum vertical displacement in the middle part reaches $461.2 \mathrm{~mm}$, The minimum displacement is $109.9 \mathrm{~mm}$, with a difference of $351.3 \mathrm{~mm}$. The maximum vertical displacement in the lower region reaches $401.2 \mathrm{~mm}$, and the minimum displacement is $94.6 \mathrm{~mm}$, with a difference of $306.6 \mathrm{~mm}$. The influence heights of overlying strata in the dip direction are also different, with the maximum influence ranges of $52.2 \mathrm{~m}$ in the upper region, $51.3 \mathrm{~m}$ in the middle region and $50.2 \mathrm{~m}$ in the lower region.

\section{Main conclusions}

Through field measurement, it can be found that the ground pressure behavior of 94101 working face is asymmetric and sequential in the process of mining; the average values of roof weighting in three areas of the inclined direction of the working face are $5994 \mathrm{kN}$, $5624 \mathrm{kN}$ and $5727 \mathrm{kN}$ respectively, the initial weighting steps are $36.80 \mathrm{~m}, 38.1 \mathrm{~m}$ and $42.10 \mathrm{~m}$ respectively, and the periodic weighting steps are $14.5 \mathrm{~m}, 15.6 \mathrm{~m}$ and $17.6 \mathrm{~m}$ respectively. The leading bearing stress and deformation of surrounding rock of material tunnel and valve tunnel also show asymmetry, and the rock pressure of material tunnel and upper area of working face is obviously larger. Through theoretical analysis, it can be seen that the upper goaf has an impact on the lower working face in the mining process of the inclined coal seam with small coal pillar to protect the roadway, which is mainly manifested by the superposition of advanced supporting pressure and lateral supporting pressure of the upper goaf. Under the superposition of supporting pressure, the lower gangue, coal seam and direct roof are further compressed and sunk, and the stress release in the upper area of the working face in this section increases.

According to the numerical simulation study, the displacement and roof stress release in the upper part of the working face are larger than those in the middle and lower part of the working face, which is basically consistent with the measured data. It shows that the goaf in the upper part of the inclined coal seam working face has an impact on the mining of the working face in this section, and it is easy to cause the mine pressure disaster.

\section{References}

1. Zhang baiwang. study on the importance of coal resources integration in coal economic development [J]. modern economic information, 2019(09):362.

2. Meng Xiangjun. Coal side support technology for gob-side entry driving in fully mechanized top-coal caving face based on basic top fault position [J]. Coal Science and Technology, 2020,48(01):61-68.

3. Mi Wenbao, Wei Hui. Study on reasonable pillar size of gob-side entry driving in deep thick coal seam face [J]. China Coal, 2016,42(06):67-70.

4. Zhao Jiyu. Research on automatic analysis technology of mine pressure behavior law in working face based on support working resistance [D]. Shandong University of Science and Technology, 2017.

5. Duan Marshal, Fang Jin. Study on optimization of coal pillar width in adjacent working face of high mining depth and high stress coal seam [J]. Shandong Coal Science and Technology, 2019(05):71-73.

6. Wei li, Qi Wei, Wu Xinghui. Study on stress evolution and numerical simulation of surrounding rock in deep mining based on borehole stress monitoring [J]. Gold, 2019,40(05):27-32.

7. Lv youchang, He Zhiqiang, Wang Yingwei, et al. the law of mining stress appearance in deep mines over 1000 meters $[\mathrm{J}]$. journal of coal science, 2019,44(05):1326-1336.

8. Zhang Wenquan. Study on borehole stress monitoring of fully mechanized top-coal caving mining roadway in extra-thick coal seam [J]. Shandong Coal Science and Technology, 2018(06):174-175+178.

9. Tan Wei, Huang Mingqing. Stress and displacement monitoring during the mining process of the ore body in the stress concentration area[J]. Non-ferrous metals (mining part), 2018, 70(02): 84-87. 